\title{
Concurrent Amphetamine and Methamphetamine Use Among Clients of Opioid Maintenance Treatment Programs in Golestan, Iran
}

\author{
Ahmad Danesh ${ }^{1}$ and Alireza Noroozi (iD) ${ }^{2,3,{ }^{*}}$ \\ ${ }^{1}$ Golestan Research Center of Psychiatry, Golestan University of Medical Sciences, Gorgan, Golestan, Iran \\ ${ }^{2}$ Iranian National Center for Addiction Studies, Tehran University of Medical Sciences, Tehran, Iran \\ ${ }^{3}$ Neuroscience and Addiction Studies Department, School of Advance Technologies in Medicine, Tehran University of Medical Sciences, Tehran, Iran \\ "Corresponding author: Iranian National Center for Addiction Studies, Tehran University of Medical Sciences, Tehran, Iran. Tel: +98-2155421144, Fax: +98-2155412232, Email: \\ a_r_noroozi@yahoo.com
}

Received 2018 May 03; Revised 2019 February 15; Accepted 2019 May 21.

\begin{abstract}
Background: Concurrent use of stimulants during opioid maintenance treatments (OMTs) negatively impacts the treatment outcomes.

Objectives: The aim of this study is to evaluate the prevalence and correlation of amphetamine and methamphetamine use among OMT clients in Golestan province-Northeast of Iran.

Methods: In a cross-sectional study, 750 OMT clients were recruited through a two-stage cluster sampling. Face-to-face interviews were conducted to complete the study questionnaire. Urine samples were also taken to perform rapid drug testing for morphine, amphetamine, methamphetamine, tramadol, cannabis, and benzodiazepines. Survey analysis command in STATA was used to estimate the prevalence of drug use among the target population.

Results: In this study, 8.1\% (95\% CI:3.6 to 12.6) of the participants had positive urine sample for amphetamine or methamphetamine. Also, $41.8 \%$ (95\% CI: 34.4 to 49.1) of the clients had positive samples for morphine. The urine positivity rate of morphine was significantly higher among those who had positive urine sample for amphetamines (68.3\%; 95\% CI: 51.7 to 84.9 versus $39.4 \% 95 \%$ CI: 31.3 to 47.6). In multivariate analysis, lifetime alcohol consumption (adjusted OR: 2.8, 95\% CI 1.5 to 5.5) and history of imprisonment (adjusted OR: 2.2, 95\% CI: 1.0 to 4.6) were associated with positive urine sample for amphetamines.

Conclusions: Simultaneous use of amphetamines among clients of OMTs was considerable. It is recommended to regularly test all OMT clients for concurrent use of stimulants. This is particularly important for clients with past history of alcohol consumption or imprisonment.
\end{abstract}

Keywords: Methamphetamine, Amphetamine, Opioid Substitution Treatment, Iran

\section{Background}

There has been an increasing trend of amphetamine use in many parts of the world in recent years $(1,2)$. Amphetamines negatively affect the productivity, health and social wellbeing, and criminal status of their users (3-6). Additionally, amphetamine use can raise the likelihood of HIV transmission by increasing high-risk sexual behaviors, including unprotected sexual activity and multiple sex partners. The risk of HIV transmission could be even higher among those who use amphetamines via injection (7).

Methamphetamine use is also reported among patients receiving opioid maintenance treatments (OMT) (8, 9 ). It has been reported that people who use opioids might initiate amphetamines use to obtain pleasure and/or im- prove their mood, energy, performance, and sexual desires (10). Nowadays, OMT programs with methadone, buprenorphine, and opium tincture (OT) are available in Iran through a large network of outpatient clinics (11). The concurrent use of amphetamines could negatively affect adherence to OMTs and antiretroviral (ARV) treatments (12, 13). Furthermore, polysubstance use raises the risk of premature death due to overdose (14). Some domestic studies provided preliminary evidence for the effectiveness of behavioral interventions to treat amphetamine use during OMTs $(15,16)$.

\section{Objectives}

In order to measure the trend of amphetamine use among OMTs clients (17), this study evaluated the preva- 
lence and correlation of amphetamine and methamphetamine use among clients of OMTs treatment centers in Golestan, a province located in the Northeast of Iran. Golestan has a population of 1.87 million; most live in urban areas (53.7\%) (18). According to a household survey conducted by the Iranian Drug Control Headquarter in 2011, the prevalence of drug dependence in Golestan province was $2.41 \%$ among 15-64-year olds (19).

A Golestan cohort study reported $17 \%$ prevalence of opium use among people above 40 years of age (20), a risk factor which was associated with higher risks for gastric adenocarcinoma (21) and premature death (22).

\section{Materials and Methods}

\subsection{Study Design}

This was a cross-sectional study of 750 clients receiving OMTs, including methadone, buprenorphine, and OT maintenance treatments. Outpatient drug treatment clinics providing OMTs are certified treatment centers that are generally run by the private sector. At these clinics, multidisciplinary teams of trained general physicians, nurses, and clinical psychologists provide services for people with drug use disorders (14).

\subsection{Study Sites}

Study participants were recruited from April to October 2015 from 25 outpatient drug treatment clinics in Golestan Province, Iran.

\subsection{Participants}

To be eligible for the study, the participants had to provide informed consent, be at least 18 years of age, and enroll in methadone, buprenorphine, or OT maintenance treatment for at least 1 month. We used a two-stage cluster sampling with stratification based on the location of OMT centers: 13 centers from Gorgan (the capital of Golestan Province) and 12 centers from other towns in Golestan province. The centers were randomly selected from a registry of all OMT centers that was provided by the vicechancellor in Treatment Affairs of Golestan University of Medical Sciences (GoUMS). After selecting the centers, we used a convenience sampling to recruit the participants from clients referred to the selected centers on the day of sampling (30 cases from each center). The process of selecting centers was without substitution and none of the centers was sampled twice.

\subsection{Measurements}

Face-to-face interviews were conducted to complete study questionnaire. Information about history of substance use and imprisonment, post history of HIV testing, HIV-related high-risk behaviors, and comprehensive knowledge about HIV transmission were collected by using this questionnaire. We defined comprehensive HIV knowledge as knowing two correct ways to prevent HIV and rejecting three misconceptions about HIV.

Reliability of the questionnaire was tested on a sample of 20 OMT clients. To validate participants' responses on recent drug usage, a rapid urine test (manufactured by the CORE Company) was done for opioids (morphine and tramadol), stimulants (amphetamine and methamphetamine), cannabis, and sedative and hypnotic prescriptions (benzodiazepines).

\subsection{Study Procedure}

Trained interviewers, who were familiar with the subject and the target group, administered the face-to-face interviews. In order to control the quality of the interviews, the research team conducted regular checks on the completed questionnaires throughout the implementation process.

The study protocol and questionnaires were approved by the Ethics Committee of GoUMS (code: IR.GOUMS.REC.1394.112). Informed consent was obtained for completing the study questionnaire and collecting urine samples. People who declined enrollment were assured that they would not be affected by this decision. All data gathering procedures were conducted anonymously.

\subsection{Data Analysis}

Survey analysis commands in STATA were used to estimate the prevalence of drug use among participants. A Logistic regression model was run to identify correlations of concurrent stimulant use among clients of OMT program.

\section{Results}

A total of 750 clients from 25 OMT centers were included in the study. During data cleaning, we excluded 44 participants because they were receiving assisted withdrawal (detoxification) treatments. Most participants were male (93.6\%) and on methadone maintenance treatment (methadone $89.2 \%$, buprenorphine $9.1 \%$, and opium tincture $1.7 \%$ ). The average duration of the current maintenance treatment was 38.2 months. The participation rate for providing a urine sample was $68.4 \%(n=481)$. Except 
for lifetime duration of using opium, there was no significant difference between those who gave urine samples and those who refused to provide samples in relation to socio-demographic characteristics (i.e. gender, age, education level, source of income), the current type of maintenance treatment, duration of current maintenance treatment, history of lifetime drug use, age of drug use initiation, and lifetime duration of using drug (Tables 1 and 2).

The urine samples of 55 participants (8.1\%, 95\% CI: 3.6 - 12.6) were positive for amphetamines (Table 3). Based on self-reporting, the prevalence of amphetamine/methamphetamine use at the time of starting the maintenance treatment was 3.8\% (95\% CI: 1.4 to 6.2 ). There was no significant difference between those who gave urine samples and those who declined to provide samples with regard to amphetamine/methamphetamine use at the time of starting the maintenance treatment ( $P$ $=0.428$ ). The urine samples of clients on buprenorphine maintenance treatment were negative for amphetamines $(n=40)$. The participants who had positive urine tests for amphetamines while receiving opioid maintenance treatment were less likely to engage in full-time employment and had lower incomes. Moreover, the history of drug injection, imprisonment, lifetime alcohol consumption, and lifetime excessive use of alcohol ( 6 or more standard drinks in a single day) were significantly higher in patients who had positive results for amphetamines. This group even had significantly greater years of regular alcohol consumption and the number of imprisonment compared to the rest of participants who provided urine samples (Table 4). The urine amphetamines positivity rate, broken down by clients' characteristics, is given in Table 5 . In the logistic regression model, there were statistically significant associations between the positivity rate of amphetamines and the history of imprisonment (adjusted OR: 2.8, 95\% CI: 1.5 to 5.5), and lifetime alcohol consumption (adjusted OR: 2.2, 95\% CI:1.0 to 4.6$)$.

There was a 9.7\% (95\% CI: 6.2 to 13.2) positive urine sample rate for cannabis. The urine samples of all clients who were on OT were negative for cannabis $(n=7)$. Regarding the use of cannabis at the time of starting opioid maintenance treatment, there was no significant difference between those who gave urine samples and those who declined to provide samples $(\mathrm{P}=0.185)$. Concurrent benzodiazepine use was high among the participants; 39.2\% (95\% CI: 25.0 to 53.5 ). The positivity rate was higher in those who had positive urine samples for amphetamines (61.0\%; 95\% CI: 44.0 to 78.0 versus $37.2 \%$ 95\% CI: 21.7 to 52.8 ). The univariate analysis revealed that the difference was statistically significant $(\mathrm{P}=0.001)$. Considering the tramadol,
12.4\% (95\% CI: 9.1 to 15.7) of the participants had positive urine tests (Table 3 ).

Furthermore, $41.8 \%$ (95\% CI: 34.4 to 49.1 ) of the participants on methadone or buprenorphine $(n=472)$ had positive urine tests for morphine (Table 3 ). The positivity rate was higher in those who had positive urine samples for amphetamines (68.3\%; 95\% CI: 51.7 to 84.9 versus 39.4\% 95\% CI: 31.3 to 47.6 ). The average dose of methadone and buprenorphine in subjects undergoing maintenance treatment was $60.0 \mathrm{mg}$ (95\% CI: 54.6 to 65.5 ) and $3.4 \mathrm{mg}$ (95\% CI: 2.9 to 3.9), respectively. These were the lowest methadone and buprenorphine doses recommended in national OMT protocols; however, methadone dose was not associated with urine morphine positivity rate $(\mathrm{P}=0.608)$.

Further analysis revealed that the urine positivity rate for tested drugs (i.e. morphine, cannabis, benzodiazepines, and tramadol) was significantly higher among the clients who had positive results for amphetamine use. Although the observed differences were statistically significant, the differences in the use of cannabis and benzodiazepines in these two groups should be viewed with caution because the number of positive urine cases for amphetamines was small (Table 6).

Although the probability of using condom in the last sexual contact was lower in people who had positive urine tests for amphetamines (29.1\%; 95\% CI: 14.2 to 44.0 versus 32.1\%; 95\% CI: 17.5 to 46.8$)$, the difference was not statistically significant $(\mathrm{P}=0.682)$. In addition, $15.8 \%$ (95\% CI: 6.3 to 25.3 ) of the participants had comprehensive knowledge about HIV transmission. Also, HIV knowledge among people with positive urine tests for amphetamines was not significantly different in comparison to those with negative urine tests for amphetamines $(\mathrm{P}=0.588)$. In addition, there was no significant difference between clients with positive urine tests and those with negative urine tests for amphetamines in relation to their self-perception of being at risk for $\operatorname{HIV}(\mathrm{P}=0.827)$. However, the history of performing HIV testing was significantly higher among those who had a positive urine test for amphetamines (40.9\%; 95\% CI: 28.0 to 53.7 versus $16.6 \%$; $95 \%$ CI: 10.3 to 23.3 ).

\section{Discussion}

The results of this study indicate that the prevalence of amphetamine use among OMT clients, measured by a rapid urine test, is about $8.1 \%$ (95\% CI: 3.6 - 12.6). In several national studies, the prevalence of concurrent amphetamine use among OMT clients has been reported in a range from $6 \%$ to $24 \%(8,9,23)$. It is important to note that the estimated prevalence of amphetamine use in our 
Table 1. Socio-Demographic Characteristics, Current Maintenance Treatment, and the Average Length of the Current Treatment are Categorized Based on the Contribution to Urine Sample Provision

\begin{tabular}{|c|c|c|c|}
\hline \multirow[t]{2}{*}{ Socio-Demographic Characteristics } & \multicolumn{2}{|c|}{ Urine Samples } & \multirow[t]{2}{*}{ PValue } \\
\hline & Yes & No & \\
\hline Gender & & & 0.821 \\
\hline Male & $448(93.7)$ & $208(93.3)$ & \\
\hline Female & $30(6.28)$ & $15(6.7)$ & \\
\hline Age, $y$ & $39.2(11.1)$ & $41.4(12.6)$ & 0.015 \\
\hline Education level & & & 0.976 \\
\hline Illiterate & $34(7.1)$ & $19(8.5)$ & \\
\hline Could barely read and write & $20(4.2)$ & $8(3.6)$ & \\
\hline Primary school & $92(19.2)$ & $42(18.8)$ & \\
\hline Guidance school & $151(31.5)$ & $69(30.8)$ & \\
\hline High school or diploma & $135(28.1)$ & $61(27.2)$ & \\
\hline Undergraduate or post graduate education & $48(10.0)$ & $25(11.2)$ & \\
\hline Source of income & & & 0.225 \\
\hline Full-time employment & $153(32.2)$ & $70(31.3)$ & \\
\hline Part-time employment & $213(44.8)$ & $96(42.9)$ & \\
\hline Family support & $18(3.8)$ & $11(4.9)$ & \\
\hline Charity or government support & $14(3.0)$ & $14(6.3)$ & \\
\hline No specific source of income & $77(16.4)$ & $33(14.7)$ & \\
\hline Current type of maintenance treatment & & & 0.453 \\
\hline Methadone & $432(90.2)$ & $196(87.1)$ & \\
\hline Buprenorphine & $40(8.4)$ & $24(10.7)$ & \\
\hline Tincture of opium & $7(1.5)$ & $5(2.2)$ & \\
\hline Duration of maintenance treatment, mo & $42.3(144)$ & $29.4(81)$ & 0.218 \\
\hline
\end{tabular}

${ }^{\mathrm{a}}$ Values are expressed as No. (\%).

study is lower than the rate reported in several international studies $(24,25)$.

Study participants, with positive urine tests for amphetamines, were found to have unstable employment status, lower income, and a higher history of drug injection and imprisonment. Given that the present study has a cross-sectional design, it is not possible to consider the above characteristics as causal factors. People with positive urine tests for amphetamines showed higher rates of lifetime alcohol consumption and excessive use of alcohol. It has been shown that alcohol consumption can harm physical well-being of the OMT clients and complicate their maintenance therapy (26). It should be noted that the proportion of people who use alcohol (i.e. lifetime use or lifetime excessive use of alcohol) in our study as a Muslim majority country with a total ban on alcohol use, was much lower than the reports from some other countries (27). The multivariate analysis showed that only lifetime alcohol consumption and history of imprisonment were associated with the rate of positive tests for amphetamine use. This finding is consistent with previous studies (28). Moreover, it is also in line with studies documenting a transition in Iran's drug use from an opioid-dominant use to- ward poly-substance use $(11,17,19)$.

One of the most important findings of the current study is the unexpectedly high urine positivity rate for morphine in OMT clients. There was a higher urine morphine positivity rate among patients who had positive results for amphetamines. Other studies have showed that this could end up in early drop outs and treatment failure (12). However, in the present study, the probability of having positive morphine urine test was not associated with the duration of maintenance treatment. Furthermore, a high rate of positivity for morphine was seen even among those clients who were enrolled on higher doses of methadone. This finding suggests that the probability that clients might not take their prescribed methadone doses when outside clinical supervision. This might be due to hoarding of opioid medication doses or diversion of them into the black market by clients.

The present study showed a non-significant trend for more high-risk sexual behaviors of participants who had positive results for amphetamine use compared with those who had negative results. This is in contrast to other reports that observed an association between amphetamine use and high-risk sexual behaviors $(29,30)$. One reason 
Table 2. The Past History of Drug Use (Consumption at Least Once During Life), Age of Initiation, and Average Years of a Regular Drug Are Categorized Based on the Contribution to Urine Sample Provision $(\mathrm{Yes} / \mathrm{No})^{\mathrm{a}}$

\begin{tabular}{|c|c|c|c|c|c|c|c|c|c|}
\hline \multirow[t]{2}{*}{ Drug Type } & \multicolumn{2}{|c|}{ History of Lifetime Drug Use } & \multirow[t]{2}{*}{ P Value } & \multicolumn{2}{|c|}{ Age of Drug Use Initiation } & \multirow[t]{2}{*}{ PValue } & \multicolumn{2}{|c|}{ Average Years of Regular Use } & \multirow[t]{2}{*}{ PValue } \\
\hline & Yes & No & & Yes & No & & Yes & No & \\
\hline Cigarette & $401(83.7)$ & $197(88.7)$ & 0.081 & $20.0(6.6)$ & $20.6(7.3)$ & 0.327 & $15.9 \pm 9.6$ & $17.1 \pm 10.8$ & 0.176 \\
\hline Opium & $458(96.0)$ & $215(95.6)$ & 0.774 & $22.9(8.0)$ & $23.5(7.6)$ & 0.330 & $12.1 \pm 8.4$ & $14.0 \pm 10.5$ & 0.010 \\
\hline Opium residue (Shireh) & $326(68.8)$ & $159(71.3)$ & 0.499 & $23.9(8.3)$ & $24.1(7.2)$ & 0.800 & $9.4 \pm 8.1$ & $10.0 \pm 8.3$ & 0.465 \\
\hline Heroin & $31(6.6)$ & $19(8.5)$ & 0.360 & $27.2(7.0)$ & $25.4(8.5)$ & 0.414 & $2.7 \pm 3.7$ & $2.7 \pm 4.6$ & 0.985 \\
\hline Crack heroin & $55(11.7)$ & $26(11.7)$ & 0.994 & $28.5(8.4)$ & $27.7(6.8)$ & 0.669 & $2.4 \pm 2.4$ & $2.1 \pm 2.0$ & 0.698 \\
\hline Norjezic & $10(2.1)$ & $2(0.9)$ & 0.249 & $27(3.4)$ & $25.5(2.1)$ & 0.566 & $1.2 \pm 1.1$ & $1.2 \pm 1.0$ & 0.788 \\
\hline Temjezic & $9(1.9)$ & $4(1.8$ & 0.925 & $26.1(3.4)$ & $26(1.7)$ & 0.958 & $1 \pm 1.0$ & $0.7 \pm 0.60$ & 0.611 \\
\hline Methadone $^{\mathbf{b}}$ & $125(26.2)$ & $61(27.4)$ & 0.737 & $32.3(9.5)$ & $32.7(12.2)$ & 0.839 & $1.4 \pm 1.9$ & $0.9 \pm 1.4$ & 0.148 \\
\hline Buprenorphine $^{\mathbf{b}}$ & $19(4.0)$ & $8(3.6)$ & 0.801 & $29.8(9.1)$ & $32.8(10.1)$ & 0.461 & $0.4 \pm 0.6$ & $0.3 \pm 0.5$ & 0.936 \\
\hline Opium tincture ${ }^{\mathrm{c}}$ & $1(0.2)$ & $1(0.5)$ & 0.588 & 48 & 60 & - & 1 & 1 & - \\
\hline Cannabis & $152(31.9)$ & $70(31.3)$ & 0.870 & $21.2(7.1)$ & $20.6(5.20$ & 0.494 & $3.6 \pm 5.4$ & $3.5 \pm 4.6$ & 0.897 \\
\hline Amphetamines & $61(12.8)$ & $33(14.7)$ & 0.626 & $31.7(8.0)$ & $28.7(6.1)$ & 0.071 & $31.7 \pm 8.0$ & $28.7 \pm 6.1$ & 0.071 \\
\hline Ecstasy ${ }^{d}$ & $5(1.0)$ & 3(1.3) & 0.735 & $25.4(5.4)$ & $32(5.2)$ & 0.141 & $1.2 \pm 1.3$ & - & - \\
\hline Cocaine $^{d}$ & $3(0.6)$ & $2(0.9)$ & 0.701 & $24(4.6)$ & $23.5(2.1)$ & 0.898 & - & $11.5 \pm 12.0$ & - \\
\hline Prescription opioids $\mathrm{e}^{\mathrm{e}}$ & $195(41.1)$ & $72(32.0)$ & 0.020 & $26.8(9.1)$ & $26.0(9.3)$ & 0.509 & $3.3 \pm 6.4$ & $2.5 \pm 6.4$ & 0.424 \\
\hline Sedative hypnotics & $172(36.0)$ & $69(30.7)$ & 0.295 & $30.6(10.5)$ & $32.6(12.6)$ & 0.219 & $5.5 \pm 6.8$ & $4.1 \pm 5.8$ & 0.160 \\
\hline Alcohol & $196(41.1)$ & $91(40.4)$ & 0.871 & $20.6(6.0)$ & $20.3(6.4)$ & 0.680 & $4.6 \pm 5.6$ & $5.5 \pm 7.2$ & 0.297 \\
\hline Binge drinking $f$ & $95(20.6)$ & $43(19.6)$ & 0.755 & - & 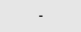 & - & - & - & - \\
\hline
\end{tabular}

Table 3. The Prevalence of Rapid Drug Tests Among Opioid Maintained Clients, Golestan, Iran (N = 481)

\begin{tabular}{|lc|}
\hline Type of Urine Test & Percent $(\mathbf{9 5} \% \mathbf{C I})$ \\
\hline Morphine & $41.8(34.4-49.1)$ \\
\hline Methamphetamine & $7.5(3.6-11.4)$ \\
\hline Cannabis & $9.7(6.2-13.2)$ \\
\hline Amphetamine & $6.5(2.8-10.2)$ \\
\hline Benzodiazepines & $39.2(25.0-53.5)$ \\
\hline Tramadol & $12.4(9.1-15.7)$ \\
\hline Amphetamine and or Methamphetamine & $8.1(3.6-12.6)$ \\
\hline
\end{tabular}

for this difference may be that people under-reported their sexual behaviors. In Iran, the topic of sex is a culturally sensitive issue that people may not be comfortable discussing. For this reason, researchers should conduct further studies that use indirect-rather than direct-methods to examine the effects of stimulants on high-risk sexual behaviors among OMT clients.

The last major finding of the study was the weak knowledge about the route of HIV transmission. It should be noted the lack of awareness about HIV transmission is not limited to clients of OMTs. In fact, this finding has already been observed in other high-risk groups in Iran, such as people who inject drugs (PWID) and prisoners (31).
One of the limitations of this study is using convenience sampling to select participants at each center. The study has also some limitations that only $68 \%$ of OMT clients agreed with providing urine samples. However, this issue did not significantly impact on the results because there were no significant differences between the personal characteristics of those who provided urine specimens and those who declined.

\subsection{Conclusions}

Given the considerable prevalence of simultaneous use of amphetamines among clients of OMTs, it is recommended to regularly test all OMT clients for stimulant use. Concurrent amphetamine/methamphetamine use seems independent of dose and course of OMT. In fact, those who are often at risk for concurrent use had a past history of alcohol consumption or imprisonment.

\section{Acknowledgments}

The authors would like to thank Ms. Tina Bagheri, Ms. Mahnaz Parnian, Ms. Atieh Samioladab, and all staff of the OMT clinics for their support and contribution to this study. 
Table 4. Socio-Demographic Characteristics and Drug Use of the Participants Are Categorized Based on Their Urine Amphetamine Test Results (i.e., Amphetamine and Methamphetamine)

\begin{tabular}{|c|c|c|c|}
\hline \multirow[t]{2}{*}{ Socio-Demographic Characteristics and History of Drug Use } & \multicolumn{2}{|c|}{ Urine Amphetamine Test Results } & \multirow[t]{2}{*}{ PValue } \\
\hline & Positive & Negative & \\
\hline Education level & & & 0.078 \\
\hline Bellow high school & $73.6(61.4-85.9)$ & $57.3(48.0-66.6)$ & \\
\hline Above high school & $26.4(14.1-38.6)$ & $42.7(33.4-52.0)$ & \\
\hline Employment & & & 0.008 \\
\hline Full time job & $20.6(1.3-39.8)$ & $35.9(29.5-42.2)$ & \\
\hline Non-full time job & $79.4(60.2-98.7)$ & $64.1(57.8-70.5)$ & \\
\hline Income status & & & $<0.001$ \\
\hline$<5000,000$ Rials (< 150 USD) per month & $40.2(14.1-66.3)$ & $22.4(15.4-29.3)$ & \\
\hline$\geq 5000,000$ Rials $(\geq 150$ USD) per month & $59.8(33.7-85.9)$ & $77.6(70.7-84.6)$ & \\
\hline Past history of drug injection (ever had drug injection) & $14.8(3.8-25.9)$ & $4.3(1.6-7.0)$ & $<0.001$ \\
\hline Lifetime alcohol consumption & $58.1(43.3-73.0)$ & $35.6(25.0-46.1)$ & 0.002 \\
\hline Excessive use of alcohol in a single day* & $36.7(21.1-52.2)$ & $16.0(10.1-21.9)$ & 0.006 \\
\hline History of imprisonment & $49.4(32.1-66.6)$ & $16.8(12.6-21.1)$ & $<0.001$ \\
\hline Years of alcohol consumption & $7.4(4.7-10.1)$ & $4.0(3.1-4.9)$ & 0.009 \\
\hline Number of time in prison & & & 0.043 \\
\hline Once & $32.5(13.7-51.2)$ & $54.9(41.1-68.7)$ & \\
\hline Two times and more & $67.5(48.8-86.3)$ & $45.1(31.3-58.9)$ & \\
\hline
\end{tabular}

${ }^{\mathrm{a}}$ Values are expressed as percent $(95 \% \mathrm{CI})$.

Table 5. Urine Amphetamines Positivity Rate Is Categorized Based on the Education Level, Employment, Income Status, Past History of Drug Injection, Alcohol Consumption (i.e. Ever Used, Excessive Use, Years of Consumption), Imprisonment, and Consumption of Other Stimulant Drugs ${ }^{\mathrm{a}}$

\begin{tabular}{|c|c|c|}
\hline Socio-Demographic Characteristics and History of Drug Use & Urine Amphetamines Test Results & P Value \\
\hline Education level & & 0.043 \\
\hline Bellow high school & $10.2(4.5-15.8)$ & \\
\hline Above high school & $5.2(1.3-9.1)$ & \\
\hline Employment status & & 0.184 \\
\hline Full time job & $4.9(0.01-9.7)$ & \\
\hline Non-full time job & $10.0(4.0-15.9)$ & \\
\hline Income status & & 0.105 \\
\hline$<5000,000$ Rials (< 150 USD) per month & $14.2(1.3-27.2)$ & \\
\hline$\geq 5000,000$ Rials ( $\geq 150$ USD) per month & $6.6(3.2-10.0)$ & \\
\hline History of drug injection (ever had drug injection) & & 0.005 \\
\hline Yes & $23.9(4.3-43.6)$ & \\
\hline No & $7.5(3.4-11.5)$ & \\
\hline Lifetime alcohol consumption & & 0.005 \\
\hline Yes & $12.6(4.5-20.7)$ & \\
\hline No & $5.4(2.4-8.5)$ & \\
\hline Lifetime excessive use of alcohol in a single day ${ }^{b}$ & & 0.001 \\
\hline Yes & $16.0(5.6-26.4)$ & \\
\hline No & $5.9(2.4-9.5)$ & \\
\hline History of imprisonment & & $<0.001$ \\
\hline Yes & $20.7(8.9-32.5)$ & \\
\hline No & $5.1(2.4-7.8)$ & \\
\hline Number of time in prison & & 0.060 \\
\hline Once & $13.4(2.0-24.7)$ & \\
\hline Two times and more & $28.1(12.1-44.0)$ & \\
\hline
\end{tabular}

${ }^{\mathrm{a}}$ Values are expressed as percent $(95 \% \mathrm{CI})$.

${ }^{\mathrm{b}}$ Six or more standard drinks (equal to $10 \mathrm{~g}$ or $12.7 \mathrm{cc}$ of pure alcohol) in a single day. 


\begin{tabular}{|c|c|c|c|}
\hline \multirow[t]{2}{*}{ Drug type } & \multicolumn{2}{|c|}{ Urine Amphetamine Test Results } & \multirow[t]{2}{*}{ P Value } \\
\hline & Positive & Negative & \\
\hline Morphine & $68.3(51.7-84.9)$ & $39.4(31.3-47.6)$ & $<0.001$ \\
\hline Cannabis & $17.7(7.0-26.5)$ & $9.1(5.6-12.6)$ & 0.034 \\
\hline Tramadol & $34.2(18.0-50.4)$ & $10.5(7.0-14.0)$ & $<0.001$ \\
\hline
\end{tabular}

${ }^{\mathrm{a}}$ Values are expressed as percent $(95 \% \mathrm{CI})$.

\section{Footnotes}

Authors' Contribution: Ahmad Danesh and Alireza Noroozi designed the study. Ahmad Danesh gathered and anlayzed the data. Alireza Noroozi and Ahmad Danesh wrote and approved manuscript.

Clinical Trial Registration Code: It is not declared by the authors.

Declaration of Interest: It is not declared by the authors. Ethical Approval: Ethics Committee of Golestan University of Medical Sciences (code: IR.GOUMS.REC.1394.112) approved the study.

Financial Disclosure: Not applicable.

Funding/Support: Golestan University of Medical Sciences, Gorgan, Iran and Iran Drug Control Headquarter.

\section{References}

1. Massaro LTS, Abdalla RR, Laranjeira R, Caetano R, Pinsky I, Madruga CS. Amphetamine-type stimulant use and conditional paths of consumption: Data from the Second Brazilian National Alcohol and Drugs Survey. Braz J Psychiatry. 2017;39(3):201-7. doi:10.1590/1516-4446-2015-1894. [PubMed: 28700012].

2. Safer DJ. Recent trends in stimulant usage. $J$ Atten Disord. 2016;20(6):471-7. doi: 10.1177/1087054715605915. [PubMed: 26486603].

3. Rognli EB, Bramness JG, Skurtveit S, Bukten A. Substance use and sociodemographic background as risk factors for lifetime psychotic experiences in a non-clinical sample. J Subst Abuse Treat. 2017;74:42-7. doi: 10.1016/j.jsat.2016.12.007. [PubMed: 28132699].

4. Zhuang SM, Chen F. Chinese adolescents and youth with methamphetamine dependence: Prevalence and concurrent psychological problems. Nurs Res. 2016;65(2):117-24. doi: 10.1097/NNR.0000000000000141. [PubMed: 26938360].

5. Degenhardt L, Roxburgh A, Black E, Bruno R, Campbell G, Kinner $S$, et al. The epidemiology of methamphetamine use and harm in Australia. Drug Alcohol Rev. 2008;27(3):243-52. doi: 10.1080/09595230801950572. [PubMed: 18368605].

6. McKetin R, Dunlop AJ, Holland RM, Sutherland RA, Baker AL, Salmon $\mathrm{AM}$, et al. Treatment outcomes for methamphetamine users receiving outpatient counselling from the Stimulant Treatment Program in Australia. Drug Alcohol Rev. 2013;32(1):80-7. doi: 10.1111/j.14653362.2012.00471.x. [PubMed: 22642414].

7. Wand H, Ward J, Bryant J, Delaney-Thiele D, Worth H, Pitts M, et al. Individual and population level impacts of illicit drug use, sexual risk behaviours on sexually transmitted infections among young Aboriginal and Torres Strait Islander people: Results from the GOANNA survey. BMC Public Health. 2016;16:600. doi: 10.1186/s12889-016-3195-6. [PubMed: 27435166]. [PubMed Central: PMC4950619].

8. Massah O, Shishehgar S. Methamphetamine dependence, psychological well-being, criminality and high risk sexual behaviors in femaleonly methadone services in Tehran and Karaj, Iran. Iran J Psychiatry Behav Sci. 2018;12(2). e61859. doi:10.5812/ijpbs.61859.

9. Dana S, Effatpanah M, Mahjoub A. The new epidemic problem of psychoactive drugs at drug treatment centers of iran: Implications for education, prevention and treatment. Iran J Psychiatry Behav Sci. 2018;12(2). e63555. doi:10.5812/ijpbs.63555.

10. Noroozi A, Malekinejad M, Rahimi-Movaghar A. Factors influencing transition to shisheh (methamphetamine) among young people who use drugs in Tehran: A qualitative study. J Psychoactive Drugs. 2018;50(3):214-23. doi: 10.1080/02791072.2018.1425808. [PubMed: 29377788].

11. Momtazi S, Noroozi A, Rawson RA. An overview of Iran drug treatment and harm reduction programs. In: el-Guebaly N, Carrà G, Galanter M, editors. Textbook of addiction treatment international perspectives. Verlag Italy: Springer; 2015. p. 543-54. doi: 10.1007/978-88-470-5322-9_25.

12. DeMaria PA Jr, Sterling R, Weinstein SP. The effect of stimulant and sedative use on treatment outcome of patients admitted to methadone maintenance treatment. Am J Addict. 2000;9(2):145-53. doi: 10.1080/10550490050173217. [PubMed: 10934576].

13. Malta M, Strathdee SA, Magnanini MM, Bastos FI. Adherence to antiretroviral therapy for human immunodeficiency virus/acquired immune deficiency syndrome among drug users: A systematic review. Addiction. 2008;103(8):1242-57. doi: 10.1111/j.1360-0443.2008.02269.x. [PubMed: 18855813].

14. De Letter EA, Piette MH, Lambert WE, Cordonnier JA. Amphetamines as potential inducers of fatalities: A review in the district of Ghent from 1976-2004. Med Sci Law. 2006;46(1):37-65. doi: 10.1258/rsmmsl.46.1.37. [PubMed: 16454462].

15. Salimi S, Effatpanah M, Mahjoub A. Motivational interviewing can facilitate entry to matrix treatment for methamphetamine dependence. Iran J Psychiatry Behav Sci. 2018;12(2). e63560. doi: 10.5812/ijpbs.63560.

16. Shakiba K, Effatpanah M, Moradi A. Cognitive-behavioral therapy for methamphetamine dependence among methadonemaintained patients. Iran J Psychiatry Behav Sci. 2018;12(2). e63615. doi: 10.5812/ijpbs.63615.

17. Shadloo B, Amin-Esmaeili M, Haft-Baradaran M, Noroozi A, GhorbanJahromi R, Rahimi-Movaghar A. Use of amphetamine-type stimulants in the Islamic Republic of Iran, 2004-2015: A review. East Mediterr Health J. 2017;23(3):245-56. doi: 10.26719/2017.23.3.245. [PubMed: 28493273].

18. Statistical Center of Iran (SCI). Selected findings of national population and housing census, 2016. Tehran: Vice Presidency for Strategic Planning and Supervision, Statistical Centre of Iran; 2016. 
19. Bureau of Planning and Information Technology. Year book of iran drug control headquarter, 2015. Presidency, Secretary of Drug Control Headquarter Publications; 2015.

20. Pourshams A, Khademi H, Malekshah AF, Islami F, Nouraei M, Sadjadi AR, et al. Cohort profile: The Golestan Cohort Study-a prospective study of oesophageal cancer in northern Iran. Int J Epidemiol. 2010;39(1):52-9. doi: 10.1093/ije/dyp161. [PubMed: 19332502]. [PubMed Central: PMC3709199].

21. Shakeri R, Malekzadeh R, Etemadi A, Nasrollahzadeh D, Aghcheli K, Sotoudeh M, et al. Opium: An emerging risk factor for gastric adenocarcinoma. Int J Cancer. 2013;133(2):455-61. doi: 10.1002/ijc.28018. [PubMed: 23319416]. [PubMed Central: PMC3644384].

22. Nalini M, Oranuba E, Poustchi H, Sepanlou SG, Pourshams A, Khoshnia $\mathrm{M}$, et al. Causes of premature death and their associated risk factors in the Golestan Cohort Study, Iran. BMJ Open. 2018;8(7). e021479. doi: 10.1136/bmjopen-2018-021479. [PubMed: 30021753]. [PubMed Central: PMC6059279].

23. Alam-mehrjerdi Z, Mokri A, Dolan K. Methamphetamine use and treatment in Iran: A systematic review from the most populated Persian Gulf country. Asian J Psychiatr. 2015;16:17-25. doi: 10.1016/j.ajp.2015.05.036. [PubMed: 26123235].

24. Heikman P, Sundstrom M, Pelander A, Ojanpera I. New psychoactive substances as part of polydrug abuse within opioid maintenance treatment revealed by comprehensive high-resolution mass spectrometric urine drug screening. Hum Psychopharmacol. 2016;31(1):44-52. doi: 10.1002/hup.2512. [PubMed: 26763789].

25. Peles E, Schreiber S, Linzy S, Domani Y, Adelson M. Differences in methylphenidate abuse rates among methadone maintenance treatment patients in two clinics. J Subst Abuse Treat. 2015;54:44-9. doi: 10.1016/j.jsat.2014.12.010. [PubMed: 25605438].

26. De Boni RB, Shepherd BE, Grinsztejn B, Cesar C, Cortes C, Padgett D, et al. Substance use and adherence among people living with HIV/AIDS receiving cART in Latin America. AIDS Behav. 2016;20(11):2692-9. doi: 10.1007/s10461-016-1398-6. [PubMed: 27091028]. [PubMed Central: PMC5069110].

27. Tran BX, Nguyen HLT, Le QNH, Mai HT, Ngo C, Hoang CD, et al. Alcohol and tobacco use among methadone maintenance patients in Vietnamese rural mountainside areas. Addict Behav Rep. 2018;7:19-25. doi: 10.1016/j.abrep.2017.11.005. [PubMed: 29450252]. [PubMed Central: PMC5805500]

28. Nyamathi A, Hudson A, Greengold B, Leake B. Characteristics of homeless youth who use cocaine and methamphetamine. Am J Addict. 2012;21(3):243-9. doi: 10.1111/j.1521-0391.2012.00233.x. [PubMed: 22494226]. [PubMed Central: PMC3794708].

29. Zule WA, Costenbader EC, Meyer WJ Jr, Wechsberg WM. Methamphetamine use and risky sexual behaviors during heterosexual encounters. Sex Transm Dis. 2007;34(9):689-94. doi: 10.1097/01.olq.0000260949.35304.22. [PubMed: 17471112].

30. Semple SJ, Grant I, Patterson TL. Perceived behavior of others and AIDS risk behavior among heterosexually-identified methamphetamine users. J Psychoactive Drugs. 2006;Suppl 3:405-13. doi: 10.1080/02791072.2006.10400604. [PubMed: 17357532].

31. Navadeh S, Mirzazadeh A, Gouya MM, Farnia M, Alasvand R, Haghdoost AA. HIV prevalence and related risk behaviours among prisoners in Iran: Results of the national biobehavioural survey, 2009. Sex Transm Infect. 2013;89 Suppl 3:iii33-6. doi: 10.1136/sextrans-2013051295. [PubMed: 23986417]. [PubMed Central: PMC3841726]. 